\title{
The effect of vitamin D on fibroblast growth factor 23: a systematic review and meta-analysis of randomized controlled trials
}

\author{
Armin Zittermann $\mathbb{1}^{1} \cdot$ Heiner K. Berthold ${ }^{2} \cdot$ Stefan Pilz ${ }^{3}$
}

Received: 22 April 2020 / Revised: 9 July 2020 / Accepted: 11 August 2020

(c) The Author(s) 2020. This article is published with open access, corrected publication 2021

\begin{abstract}
The phosphaturic hormone fibroblast growth factor 23 (FGF23) is a risk marker of cardiovascular and all-cause mortality. We therefore aimed to synthesize the evidence for the effect of vitamin D administration on circulating FGF23 concentrations. We performed a systematic review and meta-analysis of randomized, placebo-controlled trials (RCTs) in several databases from inception to January 2020. A total of 73 records were identified for full-text review, and 21 articles with 23 studies were included in the final analysis. The selected studies included 1925 participants with 8-156 weeks of follow-up. The weighted mean difference in FGF23 in the vitamin D versus placebo group was $+21 \mathrm{pg} / \mathrm{ml}(95 \%$ CI: $13-28 \mathrm{pg} / \mathrm{ml} ; P<0.001)$ with considerable heterogeneity among studies $\left(I^{2}=99 \%\right)$. The FGF23 increment was higher in patients with end-stage kidney/heart failure than in other individuals $(+300 \mathrm{pg} / \mathrm{ml}[95 \%$ CI: $41-558 \mathrm{pg} / \mathrm{ml}] \mathrm{vs} .+20 \mathrm{pg} / \mathrm{ml}$ [95\% CI: $12-28 \mathrm{pg} / \mathrm{ml}], P_{\text {interaction }}=0.03$ ), and if baseline 25 -hydroxyvitamin D concentrations were $<50 \mathrm{nmol} / 1$ instead of $\geq 50 \mathrm{nmol} / \mathrm{l}\left(+34 \mathrm{pg} / \mathrm{ml}[95 \%\right.$ CI: $18-51 \mathrm{pg} / \mathrm{ml}]$ vs. $+9 \mathrm{pg} / \mathrm{ml}[95 \%$ CI: $\left.3-14 \mathrm{pg} / \mathrm{ml}] ; P_{\text {interaction }}=0.002\right)$. Moreover, the FGF23 increment was influenced by vitamin D dose/type (vitamin D dose equivalent $\leq 2000$ IU/day: $+2 \mathrm{pg} / \mathrm{ml}[95 \%$ CI: 0-3 pg/ml]; vitamin D dose equivalent $>2000$ IU/day: $+18 \mathrm{pg} / \mathrm{ml}$ [95\% CI: 6-30 pg/ml]; administration of activated vitamin D: $\left.+67 \mathrm{pg} / \mathrm{ml}[95 \% \mathrm{CI}: 16-117 \mathrm{pg} / \mathrm{ml}] ; P_{\text {interaction }}=0.001\right)$. Results were not significantly influenced by study duration $\left(P_{\text {interaction }}=0.14\right)$, age class $\left(P_{\text {interaction }}=0.09\right)$, or assay provider $\left(P_{\text {interaction }}=0.11\right)$. In conclusion, this meta-analysis of RCTs demonstrates that vitamin D administration of $>2000 \mathrm{IU} / \mathrm{d}$ vitamin D or activated vitamin D significantly increased concentrations of the cardiovascular risk marker FGF23, especially in patients with end-stage kidney/heart failure.
\end{abstract}

\section{Introduction}

Fibroblast growth factor 23 (FGF23) plays a pivotal role in the regulation of mineral metabolism: The hormone has phosphaturic properties, augments renal calcium and sodium reabsorption, and is stimulated by high serum

Supplementary information The online version of this article (https:// doi.org/10.1038/s41430-020-00725-0) contains supplementary material, which is available to authorized users.

$\triangle$ Armin Zittermann

azittermann@hdz-nrw.de

1 Clinic for Thoracic and Cardiovascular Surgery, Herz- und Diabeteszentrum NRW, Ruhr University Bochum,

Bad Oeynhausen 32545, Germany

2 Department of Internal Medicine and Geriatrics, Bethel Clinic (EvKB), Bielefeld 33611, Germany

3 Division of Endocrinology and Diabetology, Department of Internal Medicine, Medical University of Graz, Graz 8036, Austria phosphate concentrations to maintain serum phosphate within the normal range [1, 2]. FGF23 also activates the reninangiotensin-aldosterone system and leads to cardiac left ventricular hypertrophy by a calcineurin- and nuclear factor of activated T cells (NFAT)-mediated process [3, 4]. Although FGF23 is primarily secreted by bone cells [5], cardiomyocytes are also capable of synthesizing this hormone [2].

FGF23 is an important marker of poor clinical outcome. Briefly, in patients with c-terminal FGF23 (cFGF23) values > $78 \mathrm{RU}$ (research units)/ml, the multivariable-adjusted risks of all-cause and cardiovascular mortality were $34 \%$ and $28 \%$, respectively, higher than in patients with values $<40 \mathrm{RU} / \mathrm{ml}$ [6]. Moreover, a meta-analysis of prospective cohort studies indicates that the risk of all-cause mortality rises gradually and progressively as cFGF23 increases, with a fivefold higher risk at cFGF23 values of $300 \mathrm{RU} / \mathrm{ml}$ than of $25 \mathrm{RU} / \mathrm{ml}$ [7]. The cause and effect relationship regarding the association between FGF23 and outcome is still elusive, but considering the wide use of vitamin D treatment, along with some concerns regarding potential adverse vitamin $\mathrm{D}$ effects at high doses, 
there exists a need to better characterize the vitamin D effect on FGF23.

From a pathophysiological point of view, vitamin D improves the efficacy of intestinal phosphorus absorption from $60 \%$ to $80 \%$ [8]. Higher circulating concentrations of 25-hydroxyvitamin D (25[OH]D), which is the hallmark of assessing vitamin D status, are associated with an increase in urinary phosphorus excretion [9]. In line with this, vitamin D supplementation and administration of the hormonal form of vitamin $\mathrm{D}, 1,25(\mathrm{OH})_{2} \mathrm{D}_{3}$ (calcitriol), also increase urinary phosphorus levels and may therefore stimulate FGF23 secretion [10, 11].

The present systematic review and meta-analysis therefore aimed to synthesize the effect of vitamin D administration on circulating FGF23 concentrations.

\section{Methods}

This meta-analysis was planned, conducted, and reported on the basis of a protocol that was developed in accordance with the PRISMA statement [12]. The protocol was registered at the PROSPERO international prospective register of systematic reviews as CRD42020171861.

\section{Eligibility criteria}

To be included, studies had to be a randomized controlled trial (RCT) with a control group receiving a placebo instead of vitamin D (Table 1). Interventions using a cross-over design with a placebo period were also eligible. Measurement of change in FGF23 was a necessary condition for study eligibility, and we excluded RCTs which did not report this change for each study cohort separately. We applied no language or time restrictions, and there were no limitations with regard to patient characteristics or vitamin D dose.

\section{Search strategy}

We performed a systematic literature search for publications up to 31 January 2020 in several databases, such as PubMed, Web of Science, the Cochrane Library for reports, and clinicaltrials.gov. We used the following search terms: [cholecalciferol or ergocalciferol or vitamin $\mathrm{D}$ or calcitriol or 1,25-dihydroxyvitamin $\mathrm{D}$ or $1 \alpha$ vitamin $\mathrm{D}$ or paricalcitol or activated vitamin $\mathrm{D}]$ and [supplementation or administration or use] and [RCT] and [FGF23]. We searched for the keywords in the titles and in the abstract, when available. Titles and abstracts of records identified in the primary search were screened, and all articles deemed potentially eligible for inclusion were retrieved in full-text format. Abstracts and unpublished results were not included. To identify additional papers, the reference lists of included studies and published reviews were also scanned. The search was performed independently by two researchers (AZ and HKB). Disagreements were resolved after debate by consensus.

\section{Data extraction}

We performed data extraction with the use of a protocol designed before we conducted the data searches. The following information was extracted: definition of intervention and control, change in FGF23 in each arm, and important baseline characteristics of the study population (Table 2). In cases in which vitamin D was not administered daily, we calculated the daily dose by dividing the administered dose by its frequency. Moreover, we recorded the method of FGF23 measurement, as well as the measured form of FGF23 (i.e., c-terminal or intact FGF23 [iFGF23]).

\section{Data synthesis}

We assessed mean differences in circulating FGF23 concentrations between intervention and control groups. Data are presented as weighted mean differences of the groups with their $95 \%$ confidence interval (CI). We used a more conservative random effects model to consider potential heterogeneity among studies. Information on mean and SD values was extracted from the text or from figures. When differences between baseline and in-study values were reported as median
Table 1 PICOS criteria for inclusion or exclusion of studies.

\begin{tabular}{|c|c|c|}
\hline Parameters & Inclusion criteria & Exclusion criteria \\
\hline Population & Human individuals & None \\
\hline Intervention & $\begin{array}{l}\text { Administration of vitamin D or activated } \\
\text { vitamin D }\end{array}$ & Non-oral administration \\
\hline Comparison & FGF23 change by vitamin D vs. placebo & $\begin{array}{l}\text { No reporting of baseline and/or in-study } \\
\text { FGF23 values }\end{array}$ \\
\hline Outcome & Incremental FGF23 & $\begin{array}{l}\text { No separate reporting of incremental FGF23 } \\
\text { by study group }\end{array}$ \\
\hline Study design & $\begin{array}{l}\text { Only RCTs or studies with a cross- } \\
\text { over design }\end{array}$ & No placebo group/period \\
\hline
\end{tabular}

FGF23 fibroblast growth factor 23, RCT randomized controlled trial. 
Table 2 Characteristics of 21 articles on vitamin D/activated vitamin D administration.

\begin{tabular}{|c|c|c|}
\hline & \multicolumn{2}{|c|}{$\begin{array}{l}\text { Administration of vitamin } \mathrm{D} / \\
\text { activated vitamin } \mathrm{D}\end{array}$} \\
\hline & Number & Percent \\
\hline Intervention groups & 23 & - \\
\hline \multicolumn{3}{|l|}{ Subjects } \\
\hline Intervention & 1025 & - \\
\hline Placebo & 900 & - \\
\hline \multicolumn{3}{|l|}{ Region of origin } \\
\hline Europe & 11 & 48 \\
\hline America & 8 & 35 \\
\hline Asia & 3 & 13 \\
\hline Australia & 1 & 4 \\
\hline \multicolumn{3}{|l|}{ Age } \\
\hline$<60$ years & 13 & 57 \\
\hline$\geq 60$ years & 9 & 39 \\
\hline Not specified & 1 & 4 \\
\hline \multicolumn{3}{|l|}{ Health status } \\
\hline Apparently healthy & 6 & 26 \\
\hline End-stage organ failure & 6 & 26 \\
\hline Other patients & 11 & 48 \\
\hline \multicolumn{3}{|l|}{ Study duration } \\
\hline$<52$ weeks & 18 & 78 \\
\hline$\geq 52$ weeks & 5 & 22 \\
\hline \multicolumn{3}{|l|}{ Baseline 25(OH)D (nmol/l) } \\
\hline$<50 \mathrm{nmol} / \mathrm{l}$ & 15 & 65 \\
\hline$\geq 50 \mathrm{nmol} / \mathrm{l}$ & 7 & 30 \\
\hline Not specified & 1 & 4 \\
\hline \multicolumn{3}{|c|}{ Baseline $1,25(\mathrm{OH})_{2} \mathrm{D}(\mathrm{pmol} / \mathrm{l})$} \\
\hline$<40 \mathrm{pmol} / \mathrm{l}$ & 2 & 9 \\
\hline $40-70 \mathrm{pmol} / 1$ & 6 & 26 \\
\hline$>70 \mathrm{pmol} / \mathrm{l}$ & 10 & 43 \\
\hline Not specified & 5 & 22 \\
\hline \multicolumn{3}{|l|}{ Vitamin D type } \\
\hline $\mathrm{D}_{2}$ & 3 & 13 \\
\hline $\mathrm{D}_{3}$ & 15 & 65 \\
\hline Calcitriol & 2 & 9 \\
\hline Paricalcitol & 3 & 13 \\
\hline \multicolumn{3}{|l|}{ Vitamin D dose (D2/D3) } \\
\hline$\leq 2000 \mathrm{IU} /$ day & 5 & 22 \\
\hline >2000 IU/day & 13 & 57 \\
\hline \multicolumn{3}{|l|}{ Activated vitamin D (dose) } \\
\hline$\leq 0.5 \mu \mathrm{g} /$ day & 2 & 9 \\
\hline$<0.5 \mu \mathrm{g} /$ day & 3 & 13 \\
\hline \multicolumn{3}{|l|}{ Frequency of Intake } \\
\hline Daily & 13 & 57 \\
\hline Weekly & 5 & 22 \\
\hline Monthly & 1 & 4 \\
\hline
\end{tabular}

Table 2 (continued)

\begin{tabular}{lll}
\hline & \multicolumn{2}{l}{$\begin{array}{l}\text { Administration of vitamin D/ } \\
\text { activated vitamin D }\end{array}$} \\
\cline { 2 - 3 } & Number & Percent \\
\hline Bimonthly & 1 & 4 \\
Other & 3 & 13 \\
Assay provider & & \\
Kainos & 13 & 57 \\
Immutopics & 6 & 26 \\
Other & 4 & 17 \\
\hline
\end{tabular}

and range, we used the formula by Hozo et al. [13] to estimate mean and SD. Results are given as pg/ml. If FGF23 concentrations were presented as $\mathrm{RU} / \mathrm{ml}$, we used a correction factor of 0.5 to convert FGF23 concentrations to $\mathrm{pg} / \mathrm{ml}$ [14]. Moreover, a correction factor of 7.52 was applied to convert $\mathrm{pmol} / \mathrm{l}$ into $\mathrm{pg} / \mathrm{ml}$. If an article consisted of more than one treatment arm, the number of patients included in the placebo arm was divided by the number of treatments.

The extent of between-study heterogeneity was also assessed by $I^{2}$ statistics, thereby classifying $25 \%, 50 \%$, and $75 \%$ as low, moderate, and high degrees of heterogeneity, respectively [15].

\section{Data analysis}

Several subgroup analyses were performed. To understand the degree to which the effect of vitamin D supplementation on FGF23 may be explained by its dose or the vitamin D type administered, we conducted meta-analyses by trials with daily vitamin D doses $\leq 2000$ international units (IU), $>2000 \mathrm{IU}$, and those administering activated vitamin D. To explore the potential for a disease-related effect, metaanalyses were conducted in patients without and with endstage organ failure (i.e., those with chronic kidney disease stage [CKD] 5 or awaiting a heart transplant). Additional meta-analyses were performed by baseline $25(\mathrm{OH}) \mathrm{D}$ concentrations $(<50 \mathrm{nmol} / 1$ or $\geq 50 \mathrm{nmol} / \mathrm{l})$, study duration ( $<52$ weeks or $\geq 52$ weeks), age class $(<60$ years or $\geq 60$ years), and assay provider. We also assessed the effect of achieved 25(OH)D concentrations $\quad(<100 \mathrm{nmol} / \mathrm{l}$ or $\geq 100 \mathrm{nmol} / \mathrm{l}$ ) in studies using native vitamin $\mathrm{D}$ or $25(\mathrm{OH}) \mathrm{D}$. To determine whether a statistically significant subgroup difference was detected, the test for subgroup differences from the Revman statistics program (see below) was used. This test tests the difference between the pooled effect estimates for each subgroup. All data for subgroup analyses were available from the original articles.

We conducted sensitivity analyses excluding trials that used vitamin $\mathrm{D}_{2}$, calcitriol, paricalcitol, or bolus 
administration of vitamin $\mathrm{D}_{3}$, and where baseline FGF23 differed substantially between the vitamin $\mathrm{D}$ and placebo groups.

To investigate whether publication bias might affect the validity of the estimates, we constructed funnel plots of the regression of observed effect sizes against the corresponding SEs, weighted by the inverse of the pooled variance [16]. Study quality was assessed according to a tool provided by the Cochrane Handbook for Systematic Reviews of Interventions [17].

For statistical significance, two-sided $\alpha$ was set at $P<$ 0.05 . All statistical analyses were conducted using RevMan (Review Manager. Version 5.3.: The Nordic Cochrane Centre. The Cochrane Collaboration. Copenhagen, 2014).

\section{Results}

\section{Included studies}

In total, we identified 1485 abstracts (Fig. 1). We excluded 1252 abstracts because the studies were not clinical trials, leaving 233 records for screening. Of these, we excluded 160 on the basis of screening titles and abstracts because they were not RCTs. Therefore, 73 studies were considered for systematic review by inspecting full-text articles. Of these, we excluded an additional 52 articles because they were not an RCT on vitamin D, no placebo group was

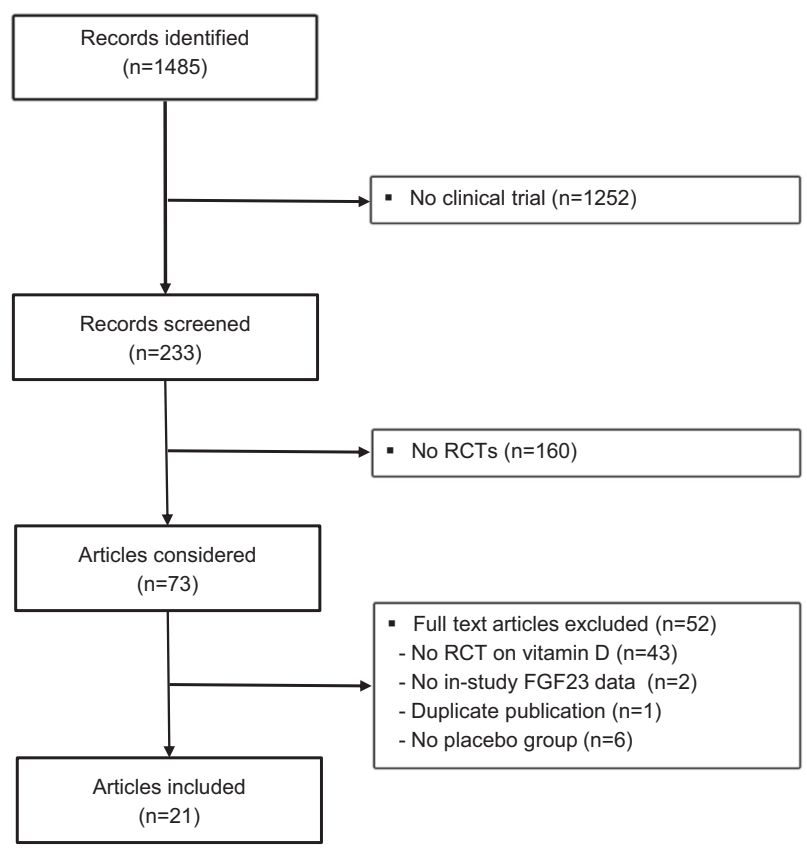

Fig. 1 Flowchart of identified and selected studies. Flowchart of selection of studies for inclusion in the meta-analysis. included, no in-study FGF23 values were presented, or because of duplicate publication. Thus, we included 21 articles in our systematic review (see Supplementary Table 1). Two articles consisted of 2 studies each, resulting in 23 studies that were finally included in our analysis. Our search did not identify articles of interest for our review in languages other than English. The characteristics of the studies are shown in Table 2. They were published between 2012 and 2019. The trials comprised 1025 study participants in the intervention group and 900 in the control groups. Out of the 23 studies, 17 studies tested native vitamin D (doses equivalent to $\leq 2000$ IU daily in 3 studies and >2000 IU daily in 14 studies, range: 400-8000 IU daily), 1 tested 25(OH)D (dose equivalent $2143 \mathrm{IU} / \mathrm{d}$ ), 5 tested activated vitamin D (two tested calcitriol [0.21 and

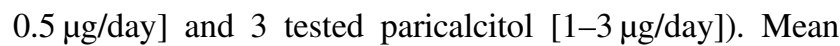
baseline $25(\mathrm{OH}) \mathrm{D}$ values were $<50 \mathrm{nmol} / \mathrm{l}$ in 15 studies and $\geq 50 \mathrm{nmol} / 1$ in 8 studies. Of the 23 studies, six were performed in patients with end-stage organ failure (CKD stage $5, n=5$; HF stage $\mathrm{D}, n=1$ ). Five studies analyzed cFGF23 values, whereas 18 studies measured iFGF23 values. Assays were provided by Kainos Laboratories $(n=13)$, Immutopics Inc. $(n=6)$, and others $(n=4)$.

\section{Synthesis of results}

Substitution with vitamin $\mathrm{D}$ or activated vitamin D increased circulating FGF23 by a mean of $21 \mathrm{pg} / \mathrm{ml}(95 \%$ CI: $14-29 \mathrm{pg} / \mathrm{ml} ; P<0.001$ ) (Fig. 2). There was an evidence for a significant heterogeneity among studies $\left(I^{2}=99 \%\right)$, confirming the need for a random effect model.

To investigate heterogeneity, we therefore evaluated in subgroup analyses the effect of vitamin D dose/type, health status, duration of vitamin D administration, baseline 25 $(\mathrm{OH}) \mathrm{D}$ concentration, age class, and method of measurement (Fig. 3). The FGF23 increment was higher in patients with end-stage kidney/heart failure than in other subjects $(+300 \mathrm{pg} / \mathrm{ml}$ [95\% CI: $41-558 \mathrm{pg} / \mathrm{ml}]$ vs. $+20 \mathrm{pg} / \mathrm{ml}[95 \%$ CI: $12-27 \mathrm{pg} / \mathrm{ml}]$ ), and was higher if baseline $25(\mathrm{OH}) \mathrm{D}$ concentrations were $<50 \mathrm{nmol} / \mathrm{l}$ instead of $\geq 50 \mathrm{nmol} / \mathrm{l}$ $(+34 \mathrm{pg} / \mathrm{ml}[95 \%$ CI: $18-51 \mathrm{pg} / \mathrm{ml}]$ vs. $+9 \mathrm{pg} / \mathrm{ml}[95 \%$ CI: 3-14 pg/ml]). Moreover, the FGF23 increment was influenced by vitamin $\mathrm{D}$ dose/type (daily vitamin $\mathrm{D}$ dose $\leq$ $2000 \mathrm{IU}:+2 \mathrm{pg} / \mathrm{ml}$ [95\% CI: $0-3 \mathrm{pg} / \mathrm{ml}$ ]; daily vitamin D dose $>2000$ IU: +18 pg/ml [95\% CI: $6-30 \mathrm{pg} / \mathrm{ml}$ ]; administration of activated vitamin $\mathrm{D}:+67 \mathrm{pg} / \mathrm{ml}[95 \% \mathrm{CI}$ : $16-117 \mathrm{pg} / \mathrm{ml}]$ ). Of the five studies on activated vitamin D, three were performed in patients with CKD stages $3-4$. The effect of activated vitamin D on FGF23 was also significantly higher in comparison to the four studies in patients with CKD stages $2-4$, who received native vitamin D $(+72 \mathrm{pg} / \mathrm{ml}[95 \%$ CI: $19-126 \mathrm{pg} / \mathrm{ml}]$ vs. $+5 \mathrm{pg} / \mathrm{ml}[95 \%$ 


\begin{tabular}{|c|c|c|c|c|c|c|c|c|c|c|c|}
\hline \multirow[b]{2}{*}{ Study or Subgroup } & \multicolumn{2}{|c|}{ Vitamin D } & \multicolumn{4}{|c|}{ Placebo } & \multicolumn{2}{|r|}{ Mean Difference } & \multirow{2}{*}{\multicolumn{3}{|c|}{$\begin{array}{c}\text { Mean Difference } \\
\text { IV, Random, } 95 \% \mathrm{Cl}[\mathrm{pg} / \mathrm{ml}]\end{array}$}} \\
\hline & Mean $[\mathrm{pg} / \mathrm{ml}]$ & $\mathrm{SD}[\mathrm{pg} / \mathrm{ml}]$ & Total & Mean $[\mathrm{pg} / \mathrm{ml}]$ & $\mathrm{SD}[\mathrm{pg} / \mathrm{ml}]$ & Total & Weight & IV, Random, $95 \% \mathrm{Cl}[\mathrm{pg} / \mathrm{ml}]$ & & & \\
\hline Burnett-Bowie 2012 & 31 & 15 & 40 & 1 & 4 & 50 & $6.8 \%$ & $30.00[25.22,34.78]$ & & $=$ & \\
\hline Carpenter 2014 & 224 & 284 & 19 & 35 & 23 & 8 & $0.3 \%$ & $189.00[60.31,317.69]$ & & $\ldots$ & \\
\hline Carvalho 2017 & 360 & 662 & 16 & -563 & 482 & 16 & $0.0 \%$ & $923.00[521.76,1324.24]$ & & & $\longrightarrow$ \\
\hline Cheng 2018 & -7 & 11 & 75 & -6 & 4 & 66 & $6.9 \%$ & $-1.00[-3.67,1.67]$ & & & \\
\hline de Boer 2013 & 64 & 3 & 11 & 4 & 8 & 11 & $6.7 \%$ & $60.00[54.95,65.05]$ & & - & \\
\hline Gravesen 2013 & 11 & 70 & 26 & 2 & 28 & 16 & $3.3 \%$ & $9.00[-21.20,39.20]$ & & - & \\
\hline Havens 2014 & 4 & 18 & 102 & 0 & 14 & 101 & $6.8 \%$ & $4.00[-0.43,8.43]$ & & & \\
\hline Kamelian 2018 & 12 & 31 & 100 & 9 & 32 & 100 & $6.4 \%$ & $3.00[-5.73,11.73]$ & & & \\
\hline Levin 2017,a & 24 & 16 & 28 & 0 & 19 & 15 & $6.0 \%$ & $24.00[12.71,35.29]$ & & 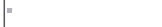 & \\
\hline Levin 2017,b & 24 & 16 & 29 & 0 & 19 & 15 & $6.0 \%$ & $24.00[12.76,35.24]$ & & $=$ & \\
\hline Macdonald 2013, a & 12 & 34 & 63 & 21 & 62 & 30 & $4.1 \%$ & $-9.00[-32.72,14.72]$ & & & \\
\hline Macdonald 2013, b & 14 & 32 & 70 & 21 & 62 & 29 & $4.1 \%$ & $-7.00[-30.78,16.78]$ & & & \\
\hline Marckmann 2012 & -26 & 40 & 25 & -428 & 549 & 24 & $0.1 \%$ & $402.00[181.80,622.20]$ & & & \\
\hline Mesinovic 2019 & 4 & 5 & 14 & -5 & 7 & 9 & $6.7 \%$ & $9.00[3.73,14.27]$ & & & \\
\hline Nygaard 2014 & 4 & 2 & 22 & 2 & 3 & 18 & $6.9 \%$ & $2.00[0.38,3.62]$ & & & \\
\hline Ramirez-Sandoval 2019 & 10,875 & 380,000 & 29 & 2,800 & 4,400 & 29 & $0.0 \%$ & $8075.00[-130237.62,146387.62]$ & $\leftarrow$ & & \\
\hline Seibert 2013 & -203 & 748 & 15 & -1 & 937 & 18 & $0.0 \%$ & $-202.00[-777.03,373.03]$ & & & \\
\hline Spoto 2018 & 112 & 6 & 44 & -21 & 33 & 44 & $6.2 \%$ & $133.00[123.09,142.91]$ & & " & \\
\hline Yadav 2018 & -15 & 7 & 58 & -7 & 9 & 59 & $6.9 \%$ & $-8.00[-10.92,-5.08]$ & & & \\
\hline Zittermann 2018 & 406 & 414 & 82 & 66 & 60 & 83 & $0.6 \%$ & $340.00[249.47,430.53]$ & & & \\
\hline \multirow[t]{2}{*}{ Total $(95 \% \mathrm{Cl})$} & & & 1025 & & & 900 & $100.0 \%$ & $21.34[13.74,28.93]$ & & 1 & \\
\hline & & & & & & & & & $\begin{array}{ccc}000 & -500 & 1 \\
& \text { Favours [vitamin D] }\end{array}$ & $\begin{array}{lc} & 1 \\
0 & 500 \\
\text { Favours [placebo] }\end{array}$ & 1000 \\
\hline
\end{tabular}

Fig. 2 Effect of vitamin D on circulating FGF23 concentrations. Data represent mean differences in circulating FGF23 concentrations between intervention and control groups with $95 \%$ confidence interval of individual studies and total effect.

Fig. 3 Subgroup analyses of vitamin $D$ on mean differences in circulating FGF23 concentrations between intervention and control groups. Boxes represent the mean values, and error bars indicate $95 \%$ confidence intervals of mean differences in FGF23 concentrations in subgroups of randomized trials. Results are given in $\mathrm{pg} / \mathrm{mL}$. Numbers indicate number of trials in each subgroup and $P$ values refer to differences between subgroups.

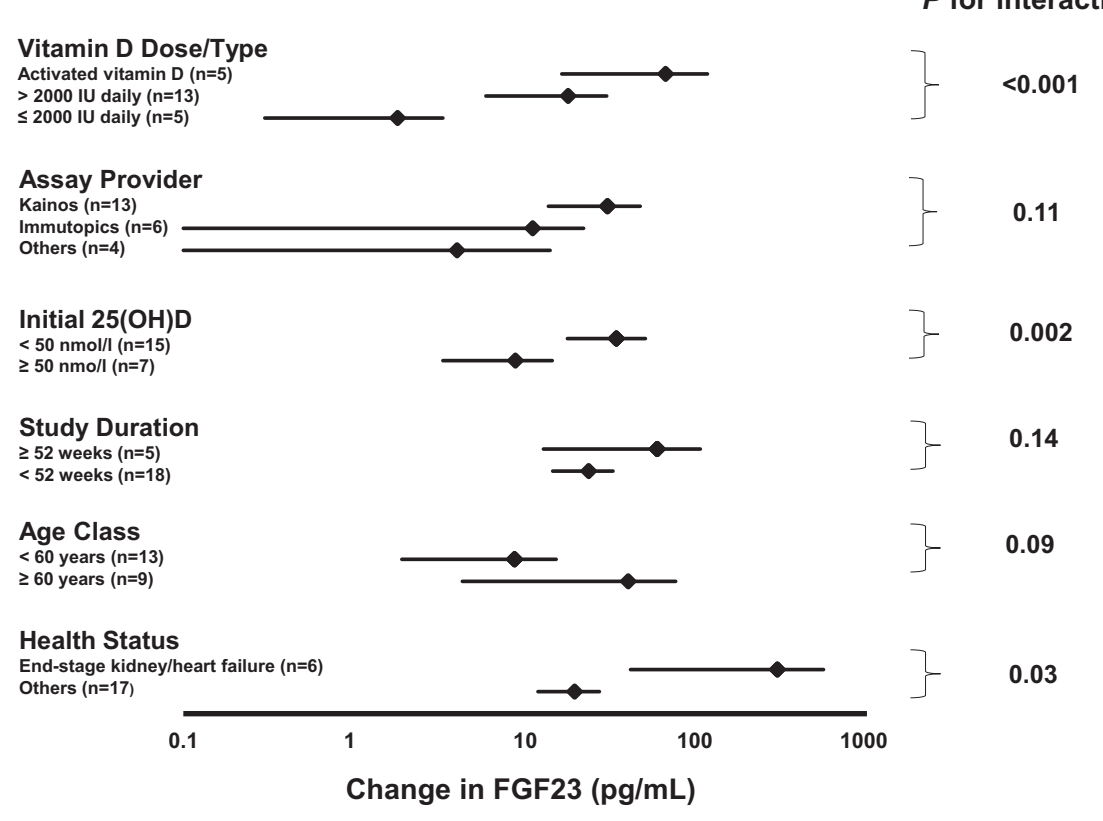

CI: -6 to $15 \mathrm{pg} / \mathrm{ml}] P=0.01)$. Results were not significantly influenced by study duration $\left(P_{\text {interaction }}=0.14\right)$, age class $\left(P_{\text {interaction }}=0.09\right)$, or assay provider $\left(P_{\text {interaction }}=\right.$ $0.11)$. In the 18 studies that used native vitamin $\mathrm{D}$ or 25 (OH)D (Supplementary Table 2), the effect on FGF23 was significantly higher in studies with achieved circulating 25 $(\mathrm{OH}) \mathrm{D}$ concentrations $\geq 100 \mathrm{nmol} / \mathrm{l}$ than in studies with achieved $25(\mathrm{OH}) \mathrm{D} \quad<100 \mathrm{nmol} / 1 \quad(65 \mathrm{pg} / \mathrm{ml} \quad[95 \% \quad \mathrm{CI}$ : 30-99 pg/ml] vs. $1 \mathrm{pg} / \mathrm{ml}$ [95\% CI: -1 to $4 \mathrm{pg} / \mathrm{ml}] P<$ $0.001)$.

\section{Sensitivity analysis}

Exclusion of one trial, whose baseline FGF23 differed substantially between the vitamin D and placebo group [18], revealed effects of vitamin $\mathrm{D}$ consistent with the main analysis (21 pg/ml [95\% CI: $14-29 \mathrm{pg} / \mathrm{ml} ; \quad P<0.001])$. Sensitivity analysis restricted to trials that used daily vitamin $\mathrm{D}_{3}$ supplements was consistent with effects of low-dose vitamin D supplementation ( $4 \mathrm{pg} / \mathrm{ml}$ [95\% CI: -1 to $4 \mathrm{pg} / \mathrm{ml} ; P=0.08]$ ). 


\section{Publication bias and study quality}

Inspection of the funnel plot of included studies does not exclude the possibility of publication bias (Supplementary Fig. 1). Regarding study quality, there was some risk of bias, especially regarding blinding of participants/personnel and incomplete outcome data presentation (Supplementary Fig. 2).

\section{Discussion}

In this meta-analysis of RCTs, we found that vitamin D administration was associated with a significant increase in FGF23 concentrations. The effect was dose-dependent and influenced by health status, and baseline as well as achieved $25(\mathrm{OH}) \mathrm{D}$ concentrations.

The vitamin D-induced mean increase in FGF23 of $21 \mathrm{pg} / \mathrm{ml}$ approximates an increase in cFGF23 of $43 \mathrm{RU} / \mathrm{ml}$ [14]. Since most assays have set the upper reference value for iFGF23 at $50-100 \mathrm{pg} / \mathrm{ml}$ and for $\mathrm{cFGF} 23$ at $100 \mathrm{RU} / \mathrm{ml}$, our results indicate a substantial vitamin $\mathrm{D}$ effect on circulating FGF23. An increase in cFGF23 of $43 \mathrm{RU} / \mathrm{ml}$ has been shown to be associated with a greater cardiovascular and all-cause mortality of approximately roughly $30 \%$ [5].

It is, however, also noteworthy that there was a null effect on FGF23 concentrations of daily vitamin D doses $\leq 2000 \mathrm{IU}$, whereas the mean increase in FGF23 was $18 \mathrm{pg} /$ $\mathrm{ml}$ at daily vitamin $\mathrm{D}$ doses $>2000 \mathrm{IU}$. Thus, our results indicate that the officially recommended daily vitamin $\mathrm{D}$ dose of 600-800 IU [19] may not affect FGF23 concentrations. This assumption is also in line with our findings that vitamin D supplementation increases FGF23 concentrations only if achieved circulating $25(\mathrm{OH}) \mathrm{D}$ concentrations are above $100 \mathrm{nmol} / \mathrm{l}$, but not if achieved 25 $(\mathrm{OH}) \mathrm{D}$ concentrations remain below $100 \mathrm{nmol} / \mathrm{l}$.

The phosphaturic hormone FGF23 is an important negative endocrine regulator of calcitriol synthesis, as well as intestinal phosphorus absorption, and may therefore contribute to the prevention of phosphorus intoxication [20]. In line with the null effect of physiologic oral vitamin D doses on FGF23 concentrations, the effect of supplemental vitamin D on circulating calcitriol is dose-dependent, with a significant lower increase at daily vitamin D doses $\leq 1000 \mathrm{IU}$ than at doses $>1000$ IU [21]. Thus, at physiologic oral vitamin $\mathrm{D}$ doses the human body may be protected from the need to increase FGF23. The absent/ small effect of physiologic amounts of supplemental vitamin D on the cardiovascular risk marker FGF23 in the present meta-analysis also supports earlier large metaanalyses showing no adverse effect of supplemental vitamin D on cardiovascular morbidity and mortality [22, 23].
Administration of activated vitamin D resulted in higher FGF23 concentrations than supplementation with native vitamin D. Activated vitamin D does not need a $1 \alpha$-hydroxylation. Therefore, in the clinical setting it is often prescribed in patients with diseases that result in limited calcitriol synthesis. In the present meta-analysis, three out of the five studies on activated vitamin D were performed in patients with CKD stages 3-4. Even in comparison to RCTs that used supplements of native vitamin $\mathrm{D}$ in patients with a similar health status (CKD stages 2-4), activated vitamin D resulted in a higher increase in FGF23. In CKD patients, administration of activated vitamin $\mathrm{D}$ tends to result in a much higher rise in circulating calcitriol than in non-CKD patients [20]. Importantly, in children on dialysis a U-shaped association has been reported between circulating calcitriol concentrations and carotid intima thickness or calcification score [24]. Although multiple studies suggest an association between the use of active vitamin $\mathrm{D}$ therapy in patients on dialysis and with CKD and improved survival, there are also many studies indicating important adverse effects of such a treatment [25]. Altogether, our data do not rule out the possibility that in some CKD patients administration of activated vitamin D contributes to the high cardiovascular risk of these patients. In a relatively large recent trial in patients undergoing maintenance hemodialysis [26], the risk of a composite measure of fatal and nonfatal cardiovascular events tended to be higher in patients receiving activated vitamin $\mathrm{D}$ versus usual care, especially when the perprotocol set was analyzed. However, it is also noteworthy that in patients with CKD stages 2-4, a well-known group of patients of a relatively high CVD risk [27], the weighted mean increase in FGF23 by native vitamin D supplementation was rather small $(+5 \mathrm{pg} / \mathrm{ml})$. Thus, there may be a relatively low risk of CVD deterioration by native vitamin $\mathrm{D}$ in this group of patients. Although observational and mechanistic studies suggest some cardiovascular protective actions of vitamin D, RCTs did not clearly document beneficial or adverse effects of vitamin D supplementation on cardiovascular outcomes [28].

In the present meta-analysis, the vitamin D-induced increase in FGF23 was the highest in patients with endstage organ failure requiring hemodialysis/awaiting heart transplantation. Notably, none of the studies in patients with end-stage organ failure used activated vitamin $\mathrm{D}$, indicating that the severity of kidney/heart failure may be even more important for the vitamin D-induced increase in FGF23 than the type of vitamin D (native or activated vitamin D). Interestingly, overexpression of FGF23 markedly reverses phosphate-induced vascular smooth muscle cells calcification [29]. As kidney function declines, circulating concentrations of FGF23 rise progressively, most probably as a consequence of rising serum phosphorus concentrations [3, 30]. Higher 
serum phosphorus concentrations in comparison with healthy controls have also been reported in patients with advanced HF [31]. Excessively enhanced FGF23 concentrations of several hundred and up to several thousand $\mathrm{pg} / \mathrm{ml}$ have been reported in both patients with end-stage renal disease and patients with end-stage heart failure [32, 33]. Since there is evidence that mortality risk rises gradually and progressively as FGF23 increases [6, 34], the vitamin D-induced mean increase in FGF23 of $300 \mathrm{pg} / \mathrm{ml}$ in patients with end-stage organ failure may be predictive for detrimental effects on health. The clinical relevance of our findings, in particular the question of whether the vitamin D-induced FGF23 increase exerts potential adverse effects or is simply a beneficial defense mechanism against high phosphorus levels warrants further investigations.

The vitamin D-induced effects on FGF23 were also influenced by baseline $25(\mathrm{OH}) \mathrm{D}$ concentrations, with a significantly higher mean FGF23 increase at 25(OH)D concentrations $<50 \mathrm{nmo} / \mathrm{l}$ (FGF23: $+34 \mathrm{pg} / \mathrm{ml}$ ) than at concentrations $\geq 50 \mathrm{nmol} / \mathrm{l}$ (FGF23: $+9 \mathrm{pg} / \mathrm{ml}$ ). This can be explained by a vitamin D-induced increase in phosphorus absorption, which may reach a plateau at adequate $25(\mathrm{OH})$ D concentrations (i.e., $\geq 50 \mathrm{nmol} / \mathrm{l}$ ). However, out of the 16 studies with baseline $25(\mathrm{OH}) \mathrm{D}$ concentrations $<50 \mathrm{nmol} /$ 1 , eight were performed in CKD patients and it is also possible that results were influenced by study population characteristics, i.e., higher vitamin D-induced increase in FGF23 concentrations in patients with versus without CKD.

The present meta-analysis has the limitation that published studies used assays which measured different forms of FGF23 such as cFGF23 and iFGF23. Although a conversion factor proposed for the comparison of $\mathrm{cFGF} 23$ with iFGF23 concentrations [14], was also used in this metaanalysis, some uncertainty regarding the comparison of different FGF23 forms remains. Moreover, publication bias cannot be ruled out. It is noteworthy that funnel plots for assessing publication bias are constructed by plotting the regression of observed effect sizes against the corresponding SEs, weighted by the inverse of the pooled variance, assuming that higher SEs indicate smaller studies. In the present meta-analysis, however, standard deviations, and thus SEs, vary widely, even between studies with similar numbers of patients (Fig. 2). Consequently, the method of assessing publication bias may be questioned in this specific analysis, and publication bias may be lower than assumed by inspection of the funnel plot. In addition, the subgroup analysis of studies with daily vitamin D intakes $\leq 2000 \mathrm{IU}$ was based on three studies only. Therefore, results have to be confirmed in future analyses with more trials. Finally, there was substantial heterogeneity among studies and this heterogeneity may only partly be explained by the sensitivity analyses we performed. Nevertheless, it is noteworthy that some of the heterogeneity such as the extremely high FGF23 in the study by Ramirez-Sandoval et al. [35] ties well with the extremely low calcitriol levels in that study because FGF23 inhibits calcitriol synthesis.

In summary, this meta-analysis of RCTs shows that vitamin D administration increases concentrations of the cardiovascular risk marker FGF23. However, subgroup analyses indicate that relatively low daily doses do not influence FGF23 substantially, whereas the effect is most pronounced in patients with end-stage kidney/heart failure, and if activated vitamin $\mathrm{D}$ is given.

Author contributions AZ designed the work that led to the submission, $\mathrm{AZ}$ and $\mathrm{HKB}$ acquired data, and SP played an important role in interpreting the results. AZ drafted the manuscript and $\mathrm{HKB}$ and $\mathrm{SP}$ revised the manuscript. $\mathrm{AZ}, \mathrm{HKB}$, and $\mathrm{SP}$ approved the final version and agreed to be accountable for all aspects of the work in ensuring that questions related to the accuracy or integrity of any part of the work are appropriately investigated and resolved.

Funding Open Access funding enabled and organized by Projekt DEAL.

\section{Compliance with ethical standards}

Conflict of interest The authors declare that they have no conflict of interest.

Publisher's note Springer Nature remains neutral with regard to jurisdictional claims in published maps and institutional affiliations.

Open Access This article is licensed under a Creative Commons Attribution 4.0 International License, which permits use, sharing, adaptation, distribution and reproduction in any medium or format, as long as you give appropriate credit to the original author(s) and the source, provide a link to the Creative Commons license, and indicate if changes were made. The images or other third party material in this article are included in the article's Creative Commons license, unless indicated otherwise in a credit line to the material. If material is not included in the article's Creative Commons license and your intended use is not permitted by statutory regulation or exceeds the permitted use, you will need to obtain permission directly from the copyright holder. To view a copy of this license, visit http://creativecommons. org/licenses/by/4.0/.

\section{References}

1. Grabner A, Mazzaferro S, Cianciolo G, Krick S, Capelli I, Rotondi S, et al. Fibroblast growth factor 23: mineral metabolism and beyond. Contrib Nephrol. 2017;190:83-95.

2. Scialla JJ, Wolf M. Roles of phosphate and fibroblast growth factor 23 in cardiovascular disease. Nat Rev Nephrol. 2014;10:268-78.

3. Faul C, Amaral AP, Oskouei B, Hu MC, Sloan A, Isakova T, et al. FGF23 induces left ventricular hypertrophy. J Clin Investig. 2011;121:4393-408.

4. Böckmann I, Lischka J, Richter B, Deppe J, Rahn A, Fischer DC, et al. FGF23-mediated activation of local RAAS promotes cardiac hypertrophy and fibrosis. Int J Mol Sci. 2019;20:4634. 
5. Razzaque MS. Phosphate toxicity and vascular mineralization. Contrib Nephrol. 2013;180:74-85.

6. Brandenburg VM, Kleber ME, Vervloet MG, Tomaschitz A, Pilz S, Stojakovic T, et al. Fibroblast growth factor 23 (FGF23) and mortality: the Ludwigshafen Risk and Cardiovascular Health Study. Atherosclerosis. 2014;237:53-59.

7. Qin Z, Liu X, Song M, Zhou Q, Yu J, Zhou B, et al. Fibroblast growth factor 23 as a predictor of cardiovascular and all-cause mortality in prospective studies. Atherosclerosis. 2017;261:1-11.

8. Holick MF. Vitamin D deficiency. N. Engl J Med. 2007;357:266-81.

9. Zittermann A, Scheld K, Stehle P. Seasonal variations in vitamin D status and calcium absorption do not influence bone turnover in young women. Eur J Clin Nutr. 19981;52:501-6.

10. Trautvetter U, Neef N, Leiterer M, Kiehntopf M, Kratzsch J, Jahreis G. Effect of calcium phosphate and vitamin $\mathrm{D}_{3}$ supplementation on bone remodelling and metabolism of calcium, phosphorus, magnesium and iron. Nutr J. 2014;13:6.

11. Slatopolsky E, Cozzolino M, Finch JL. Differential effects of 19-nor1,25-(OH) (2) $\mathrm{D}(2)$ and 1alpha-hydroxyvitamin $\mathrm{D}(2)$ on calcium and phosphorus in normal and uremic rats. Kidney Int. 2002;62:1277-84.

12. Moher D, Liberati A, Tetzlaff J, Altman DG, PRISMA Group. Preferred reporting items for systematic rev and meta-analyses: the PRISMA statement. Ann Intern Med. 2009;151:264-9.

13. Hozo SP, Djulbegovic B, Hozo I. Estimating the mean and variance from the median, range, and the size of a sample. BMC Med Res Methodol. 2005;5:13.

14. Devaraj S, Duncan-Staley C, Jialal I. Evaluation of a method for fibroblast growth factor-23: a novel biomarker of adverse outcomes in patients with renal disease. Metab Syndr Relat Disord. 2010;8:477-82.

15. Higgins JP, Thompson SG. Quantifying heterogeneity in a metaanalysis. Stat Med. 2002;21:1539-58.

16. Macaskill P, Walter SD, Irwig L. A comparison of methods to detect publication bias in meta-analysis. Stat Med. 2001;20:641-54.

17. Cochrane Community (beta). Cochrane handbook for systematic reviews of interventions. www.cochrane.org/handbook. Accessed Mar 2015.

18. Seibert E, Heine GH, Ulrich C, Seiler S, Köhler H, Girndt M. Influence of cholecalciferol supplementation in hemodialysis patients on monocyte subsets: a randomized, double-blind, placebocontrolled clinical trial. Nephron Clin Pract. 2013;123:209-19.

19. Standing Committee on the Scientific Evaluation of Dietary Reference Intakes, Food and Nutrition Board, Institute of Medicine, editors. Dietary reference intakes for calcium, phosphorus, magnesium, vitamin D, and fluoride. Washington D.C.: National Academic Press; 1997.

20. Zittermann A, Ernst JB. Calciotropic and phosphaturic hormones in heart failure. Nutr Metab Cardiovasc Dis. 2016;26:971-9.

21. Zittermann A, Ernst JB, Birschmann I, Dittrich M. Effect of vitamin D or activated vitamin D on circulating 1,25-dihydroxyvitamin D concentrations: a systematic review and metaanalysis of randomized controlled trials. Clin Chem. 2015;61:1484-94.
22. Jenkins DJA, Spence JD, Giovannucci EL, Kim YI, Josse R, Vieth R, et al. Supplemental vitamins and minerals for CVD prevention and treatment. J Am Coll Cardiol. 2018;71:2570-84.

23. Barbarawi M, Kheiri B, Zayed Y, Barbarawi O, Dhillon H, Swaid B, et al. Vitamin D supplementation and cardiovascular disease risks in more than 83000 Individuals in 21 randomized clinical trials: a meta-analysis. JAMA Cardiol. 2019. https://doi.org/10. 1001/jamacardio.2019.1870.

24. Shroff R, Egerton M, Bridel M, Shah V, Donald AE, Cole TJ, et al. A bimodal association of vitamin $\mathrm{D}$ levels and vascular disease in children on dialysis. J Am Soc Nephrol. 2008;19:1239-46.

25. Gluba-Brzózka A, Franczyk B, Ciałkowska-Rysz A, Olszewski R, Rysz J. Impact of vitamin D on the cardiovascular system in advanced chronic kidney disease (CKD) and dialysis patients. Nutrients. 2018;10:E709.

26. J-DAVID Investigators, Shoji T, Inaba M, Fukagawa M, Ando R, Emoto M, et al. Effect of oral alfacalcidol on clinical outcomes in patients without secondary hyperparathyroidism receiving maintenance hemodialysis: the J-DAVID Randomized Clinical Trial. JAMA. 2018;320:2325-34.

27. Nitta K, Ogawa T, Hanafusa N, Tsuchiya K. Recent advances in the management of vascular calcification in patients with endstage renal disease. Contrib Nephrol. 2019;198:62-72.

28. Zittermann A, Pilz S. Vitamin D and cardiovascular disease: an update. Anticancer Res. 2019;39:4627-35.

29. Chen YX, Huang C, Duan ZB, Xu CY, Chen Y. Klotho/FGF23 axis mediates high phosphate-induced vascular calcification in vascular smooth muscle cells via $W n t 7 b / \beta$-catenin pathway. Kaohsiung J Med Sci. 2019;35:393-400.

30. Clinkenbeard EL, Noonan ML, Thomas JC, Ni P, Hum JM, Aref $\mathrm{M}$, et al. Increased FGF23 protects against detrimental cardiorenal consequences during elevated blood phosphate in CKD. JCI Insight 2019;4:123817.

31. Zittermann A, Schleithoff SS, Tenderich G, Berthold HK, Körfer $\mathrm{R}$, Stehle P. Low vitamin D status: a contributing factor in the pathogenesis of congestive heart failure? J Am Coll Cardiol. 2003;41:105-12.

32. Rhee H, Yang JY, Jung WJ, Shin MJ, Yang BY, Song SH, et al. Significance of residual renal function for phosphate control in chronic hemodialysis patients. Kidney Res Clin Pract. 2014;33:58e64.

33. Zittermann A, Morshuis M, Kuhn J, Pilz S, Ernst JB, Oezpeker C, et al. Vitamin D metabolites and fibroblast growth factor- 23 in patients with left ventricular assist device implants: association with stroke and mortality risk. Eur J Nutr. 2016;55:305-13.

34. Gao S, Xu J, Zhang S, Jin J. Meta-analysis of the association between fibroblast growth factor 23 and mortality and cardiovascular events in hemodialysis patients. Blood Purif. 2019;47:24-30.

35. Ramirez-Sandoval JC, Arvizu-Hernandez M, Cruz C, VazquezCantu B, Rojas-Concha LJ, Tamez L, et al. Cholecalciferol supplementation increases FGF23 in peritoneal dialysis patients with hypovitaminosis D: a randomized clinical trial. J Nephrol. 2019;32:645-59. 